\title{
Por que a informatização funciona? Estratégias de compensação dos atores no caso da prescrição médica
}

DOI: 10.3395/reciis.v2i1.159pt

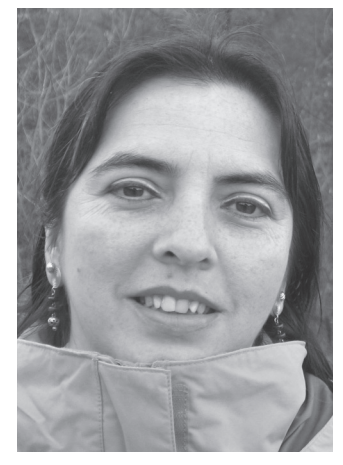

\section{Gloria Zarama-}

Vasquez

PACTE Politique-Organisa-

tions, CNRS - Université de

Grenoble

Grenoble, France

gzarama@gmail.com

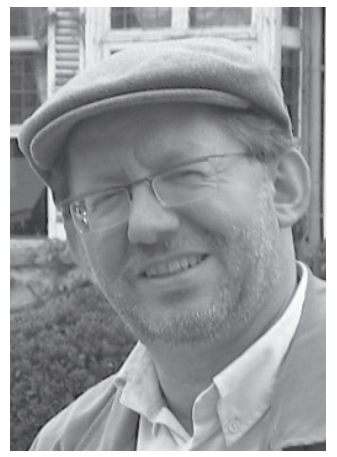

Dominique

Vinck

PACTE Politique-Organisations, CNRS - Université de Grenoble

Grenoble, France dominique.vinck@upmfgrenoble.fr

\section{Resumo}

O presente artigo trata do processo de informatização de um serviço de cuidados hospitalares tomando o caso de um software de prescrição médica. A ferramenta permite aos médicos prescrever por meio do computador o tratamento medicamentoso que os enfermeiros deverão preparar e administrar em seguida. A investigação etnográfica, no serviço hospitalar, relata a introdução da ferramenta a partir da atividade cotidiana dos enfermeiros. Destaca uma série de dificuldades com as quais os usuários se confrontam bem como as soluções que eles criam para tornar a ferramenta operacional, confiável e eficiente. O artigo relata assim as "estratégias de compensação" que os usuários desenvolvem, em especial o "trabalho de equipamento" dos suportes informáticos. O artigo mostra também que as estratégias de compensações criadas in situ pelos usuários são, em parte, invisíveis para os projetistas da ferramenta. Distantes da atividade comum dos usuários, os projetistas não percebem nem os problemas de uso nem as soluções criadas localmente. Eles atribuem o desempenho da ferramenta à qualidade da sua concepção e sua capacidade de melhorar a ferramenta que se encontra reduzida. $\mathrm{O}$ artigo convida a refletir sobre o que torna efetiva a eficiência de um sistema de informação e sobre as lições aprendidas para a concepção das ferramentas.

\section{Palavras-chave}

Informatização, hospital, compensação, invisibilidade, equipamento

\section{Introdução}

A concepção e implementação de sistemas informáticos é uma atividade que tem se tornado importante na sociedade do conhecimento. O número e a diversidade das suas aplicações atingem hoje quase a totalidade das atividades produtivas e de serviço, incluindo o domínio da saúde pública (YASNOFF et al., 2000). Numerosos métodos de concepção (ciclo de desenvolvimento ${ }^{1}$ ) são utilizados pelos projetistas e diversos métodos de acompanhamento da mudança são publicados na literatura (TAYLOR, 2003; WAGER et al., 2005). No entanto, apesar de toda esta atividade de divulgação de métodos, pesquisas revelam que os novos sistemas informáticos conhecem dificuldades e fracassos (SAUER, 1993; LYYTINEN et al., 1999; HEEKS, 2002; TAYLOR, 2003; GOLDFINCH, 2007). Os patrocinadores de novas ferra- 
mentas se defrontam com resistências e desvios de função e de uso e os usuários lamentam a falta de adequação das ferramentas. Numerosos autores explicam as falhas observadas pela suposta "resistência" dos atores diante da mudança e da novidade (PIDERIT, 2000).

Os especialistas das ciências sociais que se interessam pelos processos de inovação e pela mudança técnica nas diversas áreas das ciências como história (SMITH et al., 1994), sociologia (KLEIN et al., 2002; WILSON et al., 2002; COUTARD et al., 2007) e, principalmente, economia (ALBERTO et al., 2008), relatam as razões e a racionalidade dos usuários e explicam os comportamentos de rejeição ou de desvio. Destaca-se (ver a síntese de HACKETT et al., 2007) que as falhas seriam devidas tanto aos problemas que vêm dos projetistas (HIRSCHHEIM et al., 1999) e dos gestores da mudança quanto dos usuários. A ação concreta, individual e coletiva, dos atores em situação explica o sucesso ou o fracasso da inovação (CALLON, 1986; BERG, 1999; ORLIKOWSKI et al., 2001; LATOUR, 2005); não são, portanto, nem as qualidades intrínsecas do objeto inovador nem as características sociais dos usuários nem a sua percepção das novidades (CHIASSON et al., 2001).

$\mathrm{O}$ artigo analisa os problemas que os atores encontram ao fazerem face a um novo sistema informático que é instalado para eles e as soluções que eles desenvolvem. Interessa-se pelo modo como os usuários enfrentam as dificuldades encontradas e, em especial, pelas "estratégias de compensação"2 (FERREIRA, 1998; PINHO et al., 2003) dos sistemas, particularmente o "trabalho de equipamento"3 dos objetos. O problema é duplamente importante. Por um lado, o processo de concepção e introdução das novas ferramentas é menos eficiente do que imaginam os projetistas. Portanto é possível melhorar os métodos. Por outro lado, bons desempenhos são obtidos em campo, isso está em parte relacionado ao trabalho de compensação que vem dos usuários. Este trabalho de compensação pode provocar repercussões negativas sobre o seu trabalho, o seu bem-estar ou a sua saúde (FERREIRA, 2000). Este artigo analisa uma situação típica deste processo de construção de compensações em sistemas informáticos no caso de uma aplicação médica no meio hospitalar. O artigo caracteriza o "trabalho de compensação" que os usuários realizam. Ele relata também o problema da invisibilidade (SUCHMAN, 1996) deste trabalho e as conseqüências que isso representa para o processo de concepção e re-concepção das ferramentas.

Além do caso singular deste software de prescrição médica, a pesquisa se questiona, de uma maneira geral, sobre o que torna efetivo o desempenho de um sistema de informação. Ela sugere que se leve em consideração, seriamente, as estratégias de uso desenvolvidas pelos atores, uma vez que elas não são facilmente visíveis e que necessitam de um esforço especial de atenção e de análise.

Na primeira parte, o artigo expõe as bases conceituais que caracterizam a abordagem teórica utilizada nesta pesquisa. A segunda parte é consagrada à exposição do campo no qual a pesquisa foi realizada e à metodologia etnográfica adotada. A terceira parte considera os dados e os materiais produzidos pela pesquisa de campo. Uma vez que o trabalho é de natureza etnográfica, os dados são, portanto, essencialmente de natureza qualitativa o que implica que devem ser expostos de maneira circunstancial. Na quarta parte, o artigo retoma a problemática para discutir os dados da observação e retirar deles o significado teórico e prático. Por último, na conclusão, os autores destacam o que eles consideram ser as lições essenciais dos resultados alcançados nesta pesquisa.

\section{Referencial teórico: da sociologia da inovação e do trabalho à noção de equipamento}

Para estudar a introdução de um novo sistema informático num serviço hospitalar, a análise mobiliza a sociologia da inovação (LATOUR, 1987) que sugere seguir os atores e suas práticas concretas. No espírito da teoria do ator-rede (CALLON, 1986; LATOUR, 1987), a análise também se esforçou em considerar as entidades não-humanas associadas na ação. Em conformidade com a etnografia da atividade de concepção (VINCK, 2003), a pesquisa ficou particularmente atenta aos objetos intermediários (VINCK et al., 1995), a saber, todas as entidades materiais produzidas e mobilizadas na ação, colocadas entre os atores ou que circulam entre si. Os atores constroem redes sociotécnicas mobilizando e deslocando entidades humanas e não-humanas, negociando e redefinindo o seu papel e as suas relações. Nesta perspectiva, a priori, a integração e a eficácia de uma nova tecnologia em situação dependem das múltiplas articulações construídas (BERG, 1999) e estabilizadas entre os diversos atores e os múltiplos objetos intermediários cujo entrecruzamento constitui a trama e o quadro da atividade comum. A teoria do ator-rede traz para a análise dos sistemas de informação uma série de conceitos que permitem não analisar separadamente a tecnologia de um lado e o sistema social do outro, mas que permitem dar conta das malhas sociotécnicas (ORLIKOSWKI et al., 2001; HANSETH et al., 2004).

As noções de articulação (FUJIMURA, 1987) e de trabalho invisivel (SUCHMAN, 1996), vindo da tradição do interacionismo simbólico e da análise da ação situada, ajudam a estudar o trabalho dos enfermeiros realizado no cotidiano, o qual tem por objetivo produzir um serviço hospitalar de qualidade. A atividade de trabalho efetiva não se reduz nunca às tarefas prescritas pela organização ou pela profissão. A noção de cognição distribuída (HUTCHINS, 1995) também ajuda no estudo dos mecanismos que expandem as capacidades cognitivas dos indivíduos.

A tradição da sociologia do trabalho e da ergonomia (GUÉRIN et al., 2001) chamam nossa atenção para os detalhes da atividade das pessoas no trabalho para gerir os conflitos entre prioridades, os fluxos de informação, as exigências contraditórias, a complexidade das relações interpessoais e a variabilidade das situações de trabalho. Os ergonomistas propõem o conceito de processo de regulação entre indivíduos para falar da gestão individual e coletiva das variações das condições internas e externas 
da atividade e o controle dos seus efeitos. De acordo com Faverge (1992), o processo de regulação estrutura a atividade dos trabalhadores e a mantém de tal modo que ela se torna satisfatória para os indivíduos e para a organização. A regulação se traduz pela resistência contrária a certas exigências, pela procura de um equilíbrio, pelo autocontrole e pelo desenvolvimento de "estratégias de compensação" (FERREIRA, 1998, 2000; PINHO et al., 2003) da organização e das ferramentas de trabalho. Em sociologia do trabalho, a regulação remete também à produção de regras autônomas (REYNAUD, 1989) pelos coletivos de trabalho, as quais se diferenciam de regras de controle prescritas pela instituição, às vezes, via ferramentas de trabalho. Neste estudo, levamos em consideração as estratégias individuais e coletivas dos atores, os mecanismos de regulação e as transformações dos suportes das práticas.

Finalmente, a partir de várias pesquisas dentro dos domínios da concepção e da inovação, da qual esta pesquisa faz parte, propomos uma conceituação original da noção de equipamento para dar conta da atividade dos atores em situação que consiste em dotar os objetos intermediários de elementos adicionais (traços, símbolos ou modificações físicas) que alteram seu destino em situação. O equipamento que resulta é constituído de elementos conduzidos pelos próprios objetos que alteram a natureza e os inserem em novos usos.

\section{Uma abordagem etnográfica para o estudo da atividade comum}

A sociologia da inovação (LATOUR, 1987) sugere seguir os inovadores estudando a expressão da demanda de um patrocinador, sua reformulação negociada com os especialistas da concepção informática e, em seguida, analisando o processo de concepção das ferramentas e a sua validação. Ao seguir os profissionais da informatização e as ferramentas que eles introduzem, o pesquisador acabaria por encontrar os usuários, as suas reações e os usos que eles fazem da ferramenta (AKRICH, 1995; EDGERTON, 1998).

No entanto, a sociologia do trabalho e a ergonomia (GUÉRIN et al., 2001) nos levam a aplicar uma abordagem com base na situação de trabalho comum dos enfermeiros onde chega um novo sistema informático. Trata-se, então, de levar em consideração o ponto de vista e as práticas dos usuários. Ao contrário da sociologia da inovação, nessa abordagem o projeto deixa de lado o ponto de vista dos patrocinadores, daqueles que prescrevem ferramentas, dos projetistas e dos instaladores. A abordagem consiste, sobretudo, em considerar uma atividade produtiva na qual intervêm, entre outras ferramentas de administração, sistemas informáticos. Ao contrario das aparências, no serviço hospitalar, os sistemas informáticos não ocupam um lugar central na atividade cotidiana. Ainda que o pessoal da área médica utilize prontuários informatizados, exames ancorados em equipamentos computadorizados, certos usuários recorrem a eles apenas alguns minutos por dia. Assim, a presente pesquisa tem por objeto o estudo da atividade comum que está, muitas vezes, ligeiramente ligada ao sistema informatizado. A ferramenta, às vezes, é apenas vislumbrada ou brevemente vista na atividade da qual ela não é o centro. As técnicas e os seus usos são aprendidos a partir de um conjunto de práticas que não são necessariamente ligadas aos sistemas informáticos.

Esta maneira de proceder mostra que a informação, da qual têm necessidade os atores em situação de trabalho, é distribuída entre uma multiplicidade de suportes e atores em interação. Esta hipótese guia o entendimento do processo de integração do instrumento informático a sua situação de trabalho. O sistema é, dentro deste ecosistema, somente um elemento entre outros. Para compreender a integração do sistema, nós nos interessamos pelas práticas dos diferentes atores, qualquer que seja a sua categoria profissional ou a sua posição na organização. Trata-se de compreender a diversidade das tarefas e as atividades, a diversidade dos sistemas informáticos propostos, a diversidade dos usos e a variabilidade das práticas e do vivido em relação às ferramentas. Desta maneira, podemos considerar a divisão do saber, a coordenação das atividades, as estratégias individuais e coletivas, suas aprendizagens, as regulações implementadas pelos atores e as transformações que eles operam nas ferramentas de trabalho.

A pesquisa etnográfica começou com entrevistas no fim do ano 2002 e com um trabalho de observação durante cinco meses no ano de 2003. A pesquisa combinou observações abertas e observações orientadas às situações específicas, como visitas médicas diárias ${ }^{4}$ aos doentes, as reuniões de transmissão de informações quando da mudança de turno e as reuniões com o pessoal da informática. Tal procedimento foi completado com entrevistas com diferentes pessoas, às vezes externas, mas que intervêm no serviço hospitalar: farmacêuticos, assistente social, psicólogo, secretário, nutricionistas, suporte da área de informática, representante da direção dos enfermeiros. A pesquisa etnográfica incluiu também o acompanhamento, durante um dia ou uma noite de trabalho, de certos profissionais: enfermeira-chefe, enfermeira, auxiliares de enfermagem, residente etc. A lista de coisas a observar considera as atividades, as interações entre atores, os objetos utilizados e as práticas concretas. As observações foram anotadas num diário de campo. A pesquisa consistiu também em restituir aos atores do serviço observado os resultados intermediários alcançados. Tais restituições constituíram momentos propícios de discussão entre os atores quando se chegava à produção de novos acordos entre eles em relação à organização do trabalho e ao uso da ferramenta. Por último, uma pesquisa complementar foi realizado durante o ano de 2008 objetivando testar a perenidade de certas observações produzidas em 2003.

A seguir, na exposição dos resultados, começaremos por caracterizar o campo pesquisado e descrever as dificuldades, e respectivas razões, com as quais os profissionais são confrontados. Serão caracterizadas também as estratégias desenvolvidas por eles para fazer face a essas dificuldades e para tornar confiável e eficiente a função que o sistema supostamente realizaria. 


\section{Em campo: uma unidade de cuidados médico-hospitalares}

$\mathrm{Na}$ unidade hospitalar, pertencente a um grande hospital público universitário da França, trabalham cerca de cinqüenta pessoas. Elas são responsáveis por cuidar de doentes, em sua maioria, idosos e dependentes, que sofrem de câncer pulmonar, dos quais uma parte morre durante o tratamento. A unidade tem a reputação de ser aberta em relação às novas tecnologias da informação. Ela é qualificada como unidade-piloto, ou mesmo como vitrine para visitantes (médicos ou informáticos de outros hospitais) da informatização hospitalar.

A unidade divide-se em duas partes: uma corresponde ao "hospital diurno" para doentes que vêm em consulta externa e que fazem tratamento de quimioterapia (10 leitos), a outra é a da internação onde os doentes permanecem por várias semanas em função do seu caso (14 leitos). O trabalho nesta unidade é considerado pelo pessoal como psicologicamente duro de suportar devido ao tipo de patologia que é gerida, à dependência dos doentes, à deterioração da doença e ao alto número de falecimentos.

Em 2003, o pessoal era formado por oito médicos, incluindo os residentes e estagiários. A equipe era composta também pelo pessoal de cuidados: uma enfermeira-chefe, treze enfermeiras, dez enfermeiros-auxiliares, cinco estagiários, fisioterapeutas e um psicólogo que intervêm em tempo parcial. Compreendia, por último, sete agentes sanitários e hospitalares, dois secretários, uma assistente social e quatro voluntários. Além disso, ocasionalmente passava uma nutricionista e assistentes de farmácia que avaliavam a reserva de medicamentos do serviço.

\section{A ferramenta: a prescrição médica informatizada}

Direcionou-se a atenção, em especial, para um sistema de prescrição médica informatizado, que permite aos médicos prescreverem no computador o tratamento medicamentoso que as enfermeiras devem preparar e administrar em seguida. O sistema serve, em princípio, de elo de ligação entre médicos e enfermeiras para a transmissão da prescrição, a edição de um plano de administração dos medicamentos (PAM), a validação da administração dos medicamentos e o acompanhamento do tratamento pelo médico. A ferramenta permite programar uma parte das ações dos enfermeiros e ajuda na distribuição de medicamentos produzindo suportes de informação legíveis como "objeto intermediário" entre atores. A concepção e aplicação do sistema tem como objetivos, almejados por vários atores, assegurar a conformidade da prescrição médica em relação às exigências regulamentares (prescrição escrita que compreende o nome do doente, do médico, uma data e uma assinatura); melhorar a qualidade da prescrição medicamentosa controlando as incompatibilidades medicamentosas; reduzir os erros de transmissões, reprodução e leitura da prescrição médica; facilitar a gestão de estoque em farmácia; assegurar a rastreabilidade da administração do tratamento.
A implementação do sistema supõe a generalização do uso do recurso da informática pelos diferentes profissionais e nas diferentes etapas do processo, incluindo aquelas realizadas no quarto do doente. Isso implica em computadores em postos fixos, computadores portáteis transportados sobre um carrinho (Figuras 1, 2 e 3), computadores de bolso e rede de antenas nos corredores da unidade que ligam os computadores portáteis à rede informática do hospital.

A aplicação do software de prescrição médica supõe também a articulação de outras aplicações informáticas relativas aos serviços administrativos que se referem ao doente, às autorizações dadas aos pessoais, à atribuição dos identificadores e senhas, à base de dados dos medicamentos, às incompatibilidades medicamentosas, à gestão de estoque da farmácia etc. Ela supõe também que médicos e enfermeiras sejam capacitados para usar o software e que um suporte técnico esteja à disposição dos usuários no caso de pane ou dificuldade.

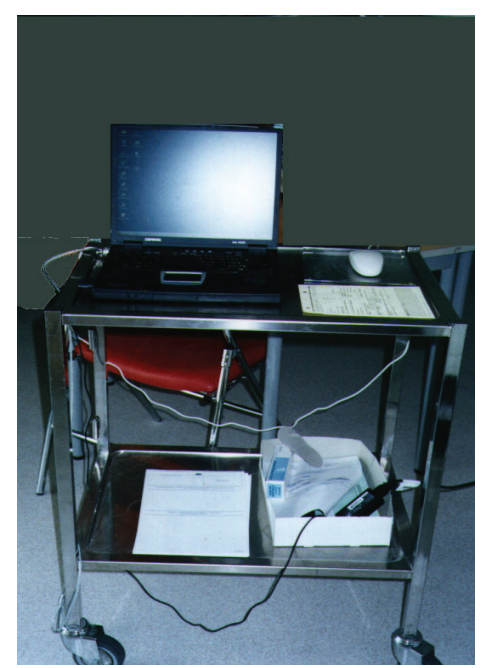

Figura 1 - Carrinho dos médicos com computador portátil em 2003.

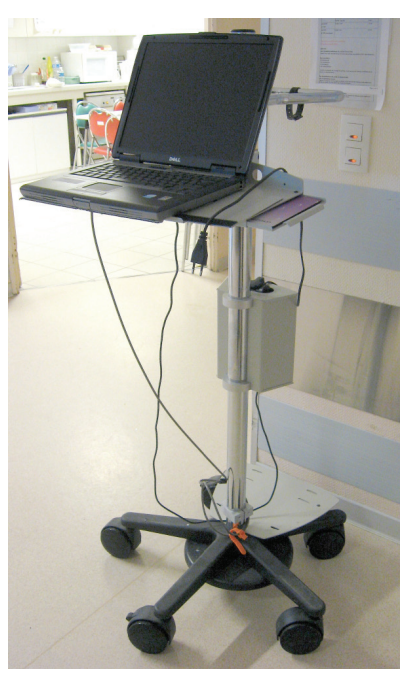

Figura 2 - Carrinho dos médicos com computador portátil em 2008. 


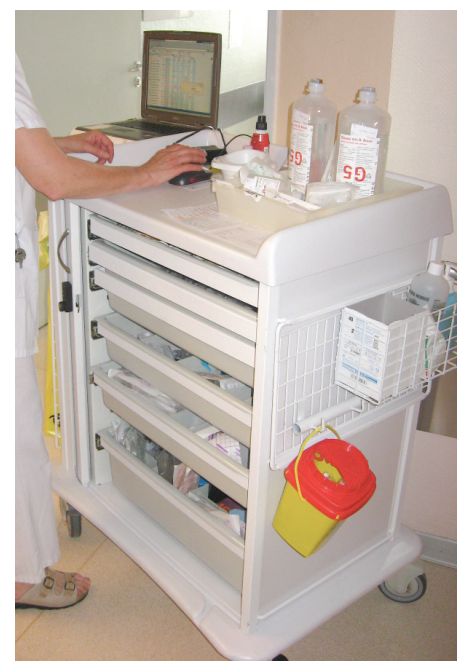

Figura 3 - Carrinho dos medicamentos com computador portátil em 2008.

Quando da observação em 2003, o instrumento era utilizado de forma intensa e sistemática, confirmando assim a sua reputação de unidade de tratamento aberta às novas tecnologias. Os médicos realizavam suas prescrições e as alteravam em função da evolução do paciente. As enfermeiras consultavam e imprimiam os tratamentos médicos e os PAM, em seguida validavam estes após ter administrado os medicamentos. O chefe de unidade interessou-se pela prescrição informatizada por muito tempo e contribuiu para o seu desenvolvimento. A unidade já tinha sido o lugar de teste, em 1996, de um software de prescrição medicamentosa. Assim, o novo software, mais eficiente, foi adotado mais facilmente uma vez que o pessoal já tinha experiência, mas, também porque havia permitido restabelecer a "paz social" entre os médicos e enfermeiras ao suprimir antigos conflitos ligados à prescrição oral. Os médicos diziam que podiam acompanhar facilmente os tratamentos prescritos e ser auxiliados pelo computador. Além disso, a divulgação da ferramenta no hospital foi acompanhada de uma série de ações como campanhas de sensibilização dos médicos e dos enfermeiros para que participassem do controle da conformidade das prescrições realizadas pelos médicos.

\section{Um sistema informático visto a partir das tensões entre lógicas profissionais}

O sistema informático restringe fortemente os médicos; ele os obriga a prescrever em conformidade com a legislação. Se eles prescrevem mal, a ferramenta os impede de validar a sua prescrição. A prescrição assim realizada é considerada como mais legível pelas enfermeiras; ela as dispensa de decifrar a caligrafia médica ou memorizar o nome do medicamento comunicado no corredor ou por telefone. Como observa um chefe de serviço: "Ela permite às enfermeiras ter uma prova da prescrição médica e assim estarem cobertas."

O sistema também obriga os médicos a racionalizar a sua prescrição, a tornar a informação (horas e doses) mais precisa e a considerar as interações medicamen- tosas. Ele traz consigo também restrições novas como o fato de limitar a lista dos medicamentos disponíveis ao nível da base de dados farmacêuticos do hospital ou de não encontrar um medicamento porque o seu nome está mal escrito. O problema aparece também quando doentes habituados a certos medicamentos reclamam sua falta, enquanto que a farmácia central não os repõem em suas bases de dados, por razões de ineficácia dos medicamentos em questão ou de existência de equivalentes menos caros. Os farmacêuticos, recusando seguir a lógica comercial, que resulta em uma multiplicação de medicamentos que são freqüentemente apenas variações uns dos outros, limitam a lista dos medicamentos acessíveis para os médicos. Um médico diz que "a ferramenta não tem por missão satisfazer todas as necessidades”. O sistema é, portanto, o lugar de confrontações entre lógicas profissionais (médicos/farmacêuticos/pessoal da informática) e entre profissionais e doentes. Neste jogo, entram também as enfermeiras que, confrontadas diariamente com a demanda e com a pressão dos pacientes e de sua família, definiram coletivamente regras tácitas em torno da aceitação de certas solicitações. A sua lógica profissional integra o apoio moral ao doente e se confronta com as vontades de racionalização que passa pela ferramenta informática. Os médicos utilizam, então, o sistema como recurso nas suas negociações com as enfermeiras e tentam recusar, segundo relato de um médico, a "satisfazer uma solicitação que está no limite do científico”. O sistema é utilizado para orientar os usuários em certas práticas ou forçá-los a afastar-se das outras práticas correntes. Isso faz parte de uma regulação de controle, que se confronta com uma regulação autônoma, tanto em relação aos médicos e enfermeiros quanto ao tratamento da solicitação dos doentes e das famílias.

A ferramenta apresenta também alguns limites que são conhecidos e destacados pelos profissionais: o fato de não permitir prescrever as quimioterapias uma vez que corresponde a mais da metade da atividade de prescrição na unidade de tratamento observada; a ausência, em 2003, de relações com o acesso aos resultados que obriga retornar ao processo no qual é utilizado o papel. Além disso, os médicos habituados "a prescrever de tudo e qualquer coisa” (relato de um médico) acusam a ferramenta de não facilitar-lhes a tarefa como, por exemplo, a prescrição de um travesseiro e um cobertor suplementar para o doente, a compota de ameixas, as bandagens, os alimentos da dieta alimentar, os aparelhos especiais, o vestuário, a passagem do psicólogo e também as mensagens dirigidas aos enfermeiros como "desejar-lhes feliz aniversário" ou "deixar entrar a sua família". O fato dos profissionais expressarem estes limites testemunha mais o desejo de ter à disposição sistemas mais eficientes do que uma rejeição a eles.

\section{As dificuldades encontradas e as soluções criadas pelos atores}

Retornamos agora à análise do uso e das dificuldades encontradas no uso do sistema e das estratégias de apropriação e de adaptação desenvolvidas pelos atores. 
O tratamento médico é introduzido por meio do computador e adaptado dia-a-dia pelos médicos. Inevitavelmente, erros são produzidos. Segundo uma enfermeira, se isso normalmente ocorre "é porque o médico não sabe utilizar o computador”. As enfermeiras, então, consideram com mais freqüência que é necessário "fazê-lo rever a sua prescrição". Isso significa duas coisas: fazer o médico reler sua prescrição para verificar se o que sai do computador é efetivamente o que ele queria descrever e fazê-lo recomeçar sua prescrição porque ela contém erros. Às vezes os médicos esquecem de validar sua prescrição antes de sair do sistema. Em outros casos, os médicos recebem mensagens de erros que eles não compreendem. Uma enfermeira, então, avalia a situação dizendo que “o problema é que o médico é responsável por uma ferramenta que está ultrapassando-o.”

Uma vez a prescrição estabelecida e validada informaticamente pelo médico, as enfermeiras podem consultá-la, a partir do seu próprio computador, para preparar a administração do tratamento. A ferramenta oferece várias visualizações e várias paginações da prescrição visando a sua impressão conforme descrito a seguir.

- Uma lista dos pacientes com data, hora, nome do médico e um campo "validado". Esta lista é consultada na tela para localizar as mudanças.

- Um sumário do tratamento para cada doente com a lista dos medicamentos prescritos, a via para a administração do medicamento, a fórmula galênica e a distribuição durante o dia, a posologia e o período de tratamento. Este documento é impresso para ser afixado no quarto do doente.

- Um "Plano de Administração dos Medicamentos" (PAM) com a lista dos medicamentos prescritos e a via para a administração do medicamento, bem como os horários previstos para administrar o medicamento. Nos campos, figura o número de comprimidos, cápsulas, frascos, unidades ou dispositivos. As enfermeiras imprimem o PAM todos os dias e o utilizam para preparar os medicamentos e, em seguida, durante a administração do tratamento, para assinalar se o medicamento foi dado ao doente ou se ele o recusou.

Logo que o PAM é impresso, as enfermeiras o examinam e fazem, manualmente, uma série de modificações nele. Elas dão destaque em algumas coisas, alteram os horários e o completam com outras indicações. Por exemplo, se um medicamento aparece duas vezes na impressão, elas bloqueiam uma das duas ocorrências para deixar somente uma. Esta prática permite evitar que uma outra enfermeira interprete as duas linhas do PAM como duas prescrições em vez de uma mesma prescrição que dura até o dia seguinte. Esta maneira de agir permite prevenir eventuais incidentes e preservar somente a informação útil para a ação. "A prescrição não é sempre muito clara", explica uma enfermeira.

Em outro exemplo, as enfermeiras completam o PAM nos casos em que o tratamento médico, por razões inexplicadas, não aparece quando da impressão. Nós observamos também que certas informações sobre o PAM são sublinhadas por marcadores fluorescentes (o nome do doente e a via da administração).
No PAM, as enfermeiras realizam também modificações nos horários. Se um medicamento está prescrito para às $18 \mathrm{~h}$, na prática, ele será dado às $16 \mathrm{~h}$, ou seja, no momento em que duas enfermeiras estejam efetivamente disponíveis: uma encarrega-se da administração dos medicamentos e a outra dos cuidados de outros doentes. O trabalho é organizado em função da disponibilidade do pessoal, não em função daquilo que é determinado no PAM. As enfermeiras organizam-se em função do "peso" dos doentes, dos cuidados a serem efetuados, das economias de escala possíveis (trabalho em série por tipo de ação) e da integração dos cuidados com um mesmo doente, bem como em função dos colegas presentes e seus hábitos. Certos cuidados devem ser realizados em conjunto e coordenados. Os horários que aparecem no PAM são fixados pelos médicos que não conhecem realmente a organização do trabalho dos enfermeiros.

Os PAM impressos são assim corrigidos, complementados, sublinhados, anotados com uma cruz para indicar que a administração do medicamento foi realizada. Assim, dizem as enfermeiras, transformados e equipados, as saídas informáticas tornam-se mais legíveis e mais práticas.

As enfermeiras defrontam-se também com um outro problema: o intervalo de tempo, variável, entre a inscrição da prescrição pelo médico e o seu aparecimento na tela do computador das enfermeiras. De acordo com os casos, é necessário esperar entre uma hora a um dia. Porém, qualquer que seja a causa do problema (pode ser que enfermeiros e médicos não tenham compreendido a lógica do sistema), para os atores, o importante é evitar cometer erros de cuidados hospitalares devido ao fenômeno da informática.

Eis alguns exemplos de desenvolvimento de soluções localizadas: um médico imprime o PAM e o entrega em mãos à enfermeira de modo que ela seja informada da modificação e leve o PAM em consideração; outro médico considera que a impressão do PAM não faz parte do seu trabalho e que as enfermeiras deveriam imprimi-lo várias vezes por dia para levar em consideração as modificações que aparecem durante o dia. Mas as enfermeiras não compartilham esta concepção da organização de trabalho que provocaria perturbações em cadeia. Às vezes, os profissionais reunem-se em torno do computador para construir uma informação compartilhada, porque a transmissão informática sozinha não é suficiente. Uma enfermeira pede ao médico a confirmação que efetivamente interrompeu o tratamento de um doente enquanto a modificação não aparece na tela. A enfermeira, não vendo aparecer a modificação que ela ouviu falar, procura verificar a informação por um circuito diferente da informática. Da mesma maneira, os médicos informam oralmente as enfermeiras das modificações que elas obtiveram no computador. Eles fazem a comunicação oral ao mesmo tempo para assegurarem-se de que a informação circula bem e para que seja rapidamente considerada. A enfermeira escreve a modificação que não aparece necessariamente no PAM, em primeiro lugar, na extremidade de um papel, que ela coloca no seu bolso, em seguida, manualmente no PAM. Ela também informa aos seus co- 
legas, oralmente, nos corredores ou nas reuniões de troca de turno. O coletivo das enfermeiras fica atento assim ao fato da modificação ser considerada e comunicada a todos os envolvidos.

A partir dos PAM corrigidos e adaptados, as enfermeiras preparam o carrinho dos medicamentos para as próximas 24 horas. Depois, quando da administração do tratamento, elas anotam manualmente no PAM se o medicamento foi dado ao doente, se ele o recusou ou a ocorrência de outra situação. Elas procedem assim a uma validação em tempo real no papel. A validação feita através do sistema informático é realizada mais tarde. Além disso, a validação informática não pode sempre ser feita em tempo real quando um medicamento, previsto no computador para às $18 \mathrm{~h}$, é administrado às $16 \mathrm{~h}$, por razões de organização do trabalho; a validação informática pode ser feita apenas após às $18 \mathrm{~h}$.

O PAM, impresso e corrigido, é levado para atualizar o carrinho dos medicamentos e depois é levado junto com o carrinho para proceder à distribuição de medicamentos em cada quarto. Uma vez o medicamento dado, o PAM é anotado. O PAM de cada doente é utilizado em seguida para proceder à validação feita através do sistema informático, no escritório das enfermeiras e, em seguida, guardados num arquivo. Certas enfermeiras validam a distribuição de medicamento seja lendo o PAM, seja de memória. A validação informática é feita em função da disponibilidade da enfermeira para esta tarefa. Para racionalizar a organização, algumas enfermeiras assinalam tudo de uma só vez, às vezes fazem isso de memória, às vezes no lugar de um colega.

Os problemas encontrados pelos atores são objeto de discussões informais e em reunião. As enfermeiras comparam e discutem as soluções que elas criam. Elas constroem acordos quanto à maneira de fazer o trabalho, por exemplo, como e quando o equipamento da versão impressa do PAM deve ser realizado.

\section{Perenidade do equipamento}

Em 2008, após terem se passado cinco anos das observações iniciais de campo, foram constatadas certas mudanças enquanto outros modos de fazer, criados pelos atores, foram perpetuados. A unidade hospitalar sofreu uma forte redução em recursos humanos e conheceu uma crise que foi traduzida em renovação de $3 / 4$ do pessoal. A falta de médico implicou em menos tempo na troca de informação; aumentando os problemas de transmissão de informações entre médicos e enfermeiras. No plano das ferramentas, várias novas aplicações informáticas foram introduzidas, o que contribuiu para reduzir a importância do recurso com suporte em papéis; mesmo para as enfermeiras, mais informações estão disponíveis no computador que acompanha com mais freqüência suas ações. Vários computadores portáteis estavam disponíveis nas unidades e foram instalados sobre os carrinhos de administração dos medicamentos que se tornaram mais práticos. A ferramenta de prescrição médica também evoluiu integrando a prescrição quimioterapêutica e outras funcionalidades como a prescrição condicional, prescrição que a enfermeira pode adaptar em função da situação sem que seja necessário que o médico faça alterações na prescrição anterior.

Globalmente, a unidade tornou-se muito mais dependente da informática e sensível, mais do que no passado, a panes. O fato de duplicar oralmente a circulação da informação em relação ao sistema informático permanece inalterado. A impressão em papel do PAM não desapareceu, assim como a sua transformação manual, quer por razões de segurança, quer por razões práticas, embora certas jovens enfermeiras pretendam abandonar o suporte em papel. Na prática, as enfermeiras, dispondo doravante de um computador portátil no carrinho de medicamentos, que se tornaram fisicamente enormes, fazem uma série de idas e vindas entre várias telas, ou entre a tela e o papel. Essas profissionais têm-se queixado do fato de passar muito tempo lidando com a informática, mas, ao mesmo tempo, reconhecem que dificilmente poderão trabalhar sem ela. Vários problemas assinalados há cinco anos persistem (prazo entre a prescrição informatizada e o aparecimento na tela do computador de uso das enfermeiras; desvio entre a prescrição que aparece na tela e o PAM), enquanto outros desapareceram em maior ou menor grau devido a uma evolução do instrumento (por exemplo, a possibilidade de validar a administração do medicamento antes da hora prevista para a sua administração).

\section{Por que, finalmente, "isso funciona"?}

Visto de longe, ou seja, a partir de uma posição médica hierárquica, afastada da atividade diária das enfermeiras, ou a partir do serviço informático, a impressão que se tem é que "isso funciona": o instrumento é utilizado amplamente, apresenta muitas vantagens e poucos problemas.

Mas, visto de perto, isto é, através de um trabalho de observação etnográfica, observa-se uma série de disfunções como: distribuição do horário que não convém à organização dos cuidados dispensados aos doentes; tratamentos que não aparecem ou que aparecem tardiamente ou que aparecem duas vezes no mesmo papel; medicamentos não previstos; impressão do PAM em várias páginas, sem reprodução dos títulos de colunas de uma página à outra; erros de transmissão de informação pelo sistema informático (talvez devido a erros de manipulação). As disfunções são desvios entre o funcionamento previsto e o que acontece efetivamente e podem ser explicadas pela desfasagem entre a utilidade (dispor de prescrições em conformidade com a legislação, as prescrições legíveis) e a usabilidade (transmissão efetiva da informação, geração de apoios operacionais - FERREIRA, 1998). Três fatores, então, estão associados a tais defasagens.

- Os desafios inerentes ao trabalho como o fato de administrar os medicamentos em horários oportunos.

- Constrangimentos ligados ao trabalho como a confiabilidade do serviço e a rastreabilidade.

- As condições para a execução das tarefas como o uso pontual do computador no curso de uma ação comum na qual o computador está normalmente pouco presente. 
A pesquisa mostra que os atores defrontam-se com diversos "pequenos" problemas ligados ao uso da ferramenta informática não porque se opõem à mudança ou às novas tecnologias, mas devido às desfasagens concretas entre os recursos oferecidos pelo instrumento e as exigências da atividade no cotidiano.

O fato dos atores se defrontarem com essas disfunções não faz com que eles desistam. Eles não rejeitam a ferramenta, mas, ao contrário, "se viram" com ela, se adaptam (memorização das senhas, transformação dos seus hábitos), transformam a sua organização (duplicação oral da informação numérica) e transformam também a ferramenta, ao menos marginalmente. Os atores corrigem e completam o PAM após a impressão (marcação, sublinhado, correção etc.) e no momento da administração dos medicamentos. Esta atividade de correção é uma atividade de regulação, que consiste em prevenir e recuperar erros, passando pela criação de estratégias de compensação da prescrição informática. Estas estratégias passam pela construção de disposições originais de objetos e de práticas que, combinados e tornados complementares, conduzem a um resultado satisfatório, segundo o ponto de vista dos atores. Eles inventam estratégias de tal forma que a sua ação torna-se, ao mesmo tempo, mais confiável (em termos de qualidade do cuidado) e mais suportável (em termos de equilíbrio pessoal). Equipando o PAM com anotações, eles transformam este objeto intermediário para fazer dele um equipamento da ação. Os atores retificam assim os suportes produzidos pelo computador, fazem marcação manual no PAM para dar peso a certas informações e dar um ordenamento preferencial às informações que não corresponde ao ordenamento impresso. Os atores complementam também as ferramentas para um novo trabalho como, por exemplo, aquele que consiste em verificar os papéis impressos para localizar e reparar erros. Esta atividade consiste em controlar os efeitos da opacidade e do difícil controle do instrumento informático. Esta regulação autônoma permite recuperar erros, constituindo-se num novo procedimento do coletivo de trabalho, uma regra da profissão construída pelos agentes para garantir a confiabilidade da execução.

O equipamento dos objetos intermediários (os papéis impressos) e a duplicação da informação são estratégias desenvolvidas pelos atores que consistem em tornar visíveis as ações, em especial quando introduzem um novo elemento, como modificação de uma prescrição. Os médicos desenvolvem estratégias de comunicação com as enfermeiras referentes às modificações introduzidas e as enfermeiras transmitem aos médicos a informação oralmente e por escrito. Eles compensam o sistema para ter mais segurança ou para permitir aos seus colegas antecipar a ação. Este investimento coletivo para equipar a ação tem ao mesmo tempo relação com seu conhecimento dos inevitáveis riscos de erros e a sua desconfiança em relação à ferramenta e também aos seus colegas. A desconfiança é grande porque, primeiro, os profissionais exprimem um forte sentimento de responsabilidade em relação à ação de cuidado hospitalar e, segundo, é difícil, às vezes, detectar a presença de um erro e lhe atribuir uma causa. A desconfiança leva os profissionais a verificar, antes que os outros, duas vezes, a imprimir, a anotar e pedir uma confirmação oral a um colega. A enfermeira assegura-se de que não há problemas relacionados à informática antes de confiar naquilo que sai da impressora, enquanto os profissionais se supervisionam reciprocamente.

A questão que se coloca é a da compreensão do que faz "aquilo funcionar". A pesquisa mostra que face àquelas dificuldades, médicos e enfermeiras criam soluções que explicam o sucesso e os desempenhos da ferramenta. As funcionalidades previstas no instrumento, sozinhas, não são suficientes para tornar o serviço eficiente. O seu controle coloca uma série de problemas que os atores observados resolvem e com os quais, finalmente, "se viram" mais do que denunciam.

\section{Conclusão}

O artigo questiona a explicação sobre os desempenhos alcançados com os sistemas informáticos em situação de trabalho numa unidade hospitalar. Longe de explicá-los pelas características intrínsecas da ferramenta, pelo sistema social ou uma combinação destas duas determinações, a explicação a ser dada encontrase em situação e na atividade comum. Os atores fazem face às dificuldades encontradas. A ferramenta em si não satisfaz às exigências profissionais da situação de trabalho. Diante dessas dificuldades, longe de rejeitar as ferramentas, os atores se empenham em transformá-la, para equipá-la com símbolos e traços, ao mesmo tempo em que se adaptam e adaptam a sua organização de maneira a compensar os limites encontrados na utilização das ferramentas.

A pesquisa identifica e caracteriza então uma série de estratégias que os atores desenvolvem para tornar confiável e eficiente a ferramenta de prescrição informatizada. O presente artigo destaca particularmente dois conceitos úteis para a análise da eficiência do sistema informático: o de estratégias de compensação, para tratar das formas de regulação que consistem em prevenir e corrigir eventuais erros; e o de equipamento, que qualifica o processo pelo qual os atores, coletivamente, negociam e constroem entidades adicionais (anotações, por exemplo) que, afixadas sobre o objeto (folha de papel, carrinho, computador) que eles transportam, alteram a sua natureza e as suas possibilidades de uso num dado espaço de troca profissional. Estas estratégias de compensação e este trabalho de equipamento não são formas de resistência à mudança, mas, ao contrário, são investimentos sociotécnicos relativos ao sistema informática feitos por atores, seus usos e a organização a fim de assegurar a confiabilidade do serviço.

Queremos destacar que estas estratégias de compensação e trabalho de equipamento são atividades apenas visíveis, sendo pouco provável que elas cheguem, naturalmente, aos projetistas e desenvolvedores de ferramentas. $\mathrm{O}$ sistema funciona porque os profissionais inventam práticas individuais e coletivas, adaptam sua organização e as ferramentas às suas necessidades. Eles compensam as dificuldades sem, no entanto, tornar visível todo o investimento individual e coletivo. 
As estratégias de compensação e o trabalho de equipamento são invisíveis também porque os próprios profissionais integram as soluções criadas nas suas rotinas, tornando-se, então, naturais e logo invisíveis, mesmo aos seus próprios olhos. A observação direta é, então, necessária para torná-las, de novo, visíveis. Resulta que a "ferramenta informática em uso" torna-se uma caixa preta, incluindo aqueles que a conceberam, que não se dão conta das razões do sucesso. Eles não vêem que o instrumento funciona também graças às ações corretivas que os usuários inventam em suas maneiras de trabalhar, em sua organização, em suas regras do trabalho coletivo, mas, também, em relação aos objetos aparentemente sem grande importância. A integração do sistema informático não é uma decorrência simplesmente de ter sido adotado pelo atores, de terem se habituado a conviver com ele e aprendido a utilizá-lo. Corresponde também a um trabalho pouco visível de transformação dos suportes, das pessoas e das práticas. "Isso funciona" finalmente porque os atores reconstroem um novo tecido de relações entre todos os elementos constitutivos das relações de trabalho num hospital, mas este trabalho de articulação é quase invisível. Pouco a pouco, novas práticas instauram-se e tornam-se tão naturais que ficam invisíveis a partir do exterior e também para os freqüentadores internos assíduos à unidade hospitalar; só um observador cuidadoso ou recém-chegado que se defronta com a cultura e os arranjos locais singulares de uma situação de trabalho podem ainda revelá-las.

Os projetistas de ferramentas, portanto, são privados de um retorno que seria precioso para o aprimoramento das ferramentas propostas. Estando longe dos espaços de uso, os projetistas de instrumentos têm a impressão de que a ferramenta funciona bem, mas estão iludidos quanto às razões deste sucesso. A questão, então, é de saber como tornar visíveis as estratégias de compensação desenvolvidas e praticadas pelos usuários e como fazer com que elas sejam levadas em consideração pelos projetistas

\section{Notas}

1. Neste ciclo, as primeiras fases correspondem à expressão das necessidades (dos clientes, dos patrocinadores) e a concepção da solução. Em seguida, na construção do produto, intervém a noção de interações curtas. Vários métodos foram desenvolvidos nesta perspectiva cuja filosofia é expressa no Agile Manifesto (Highsmith, 2002).

2. As estratégias de compensação são uma parte das estratégias de utilização como as estratégias de adaptação ou de substituição.

3. No contexto deste artigo, nós definimos o termo "Equipamento" como a ação de equipar pessoas ou objetos e também o resultado do processo decorrente desta ação.

4. A visita médica diária dura quatro horas e é feita a cada manhã com o médico-chefe (um professor universitário), os médicos residentes, os médicos estagiários e a enfermeira-chefe.

\section{Referências bibliográficas}

AKRICH, M. User representations: practices, methods and sociology. In: RIP, A.; MISA, T.; SCHOT, J. (Eds.). Managing technology in society: the approach of constructive technology assessment. London: Frances Pinter. 1995. p.167-184.

AUBERT, B. et al. A multi-level, multi-theory perspective of information technology implementation. Information Systems Journal, v.18, n.1, p.45-72, 2008. [doi:10.1 11 1/j.1365-2575.2007.00279.x]

BERG, M. Patient care information systems and health care work: a sociotechnical approach. International Journal of Medical Informatics, v.55, n.2, p.87-101, 1999.

CALLON, M. Some elements of a sociology of translation: Domestication of the scallops and fishermen of St. Brieuc Bay'. In: LAW, J. (Eds.). Power action and belief: a new sociology of knowledge?, Routledge, London, 1986. p.196-233.

CHIASSON, M.; LOVATO, C. Factors influencing the formation of a user's perceptions and use of a DSS software innovation. ACM SIGMIS Database, v.32, n.3, p. 16-35, 2001. [doi: acm.org/10.1 145/506724.506727]

COUTARD, O.; GUY, S. STS and the city: politics and practices of hope. Science, Technology \& Human Values, v.32, p.713 -734, 2007.

EDGERTON, D. De l'innovation aux usages. Dix thèses éclectiques sur l'histoire des techniques. Annales, n.4-5, p.815-837, 1998. [english version: From Innovation to Use: ten (eclectic) theses on the history of technology, History and Technology, v.16, p.1-26 1999.

FAVERGE, J.M. L'analyse du travail en terme de régulation. In: LEPLAT, J. (Coord.). L'analyse du travail en psychologie ergonomique. Toulouse (France): Éditions Octarés, 1992. p.61-8.

FERREIRA, M. Atividade, categoria central na conceituação de trabalho em ergonomia. Revista Alethéia, Canoas - RS, v.1, n.11, p.71-82, 2000.

FERREIRA, M. Utilité et utilisabilité de l'informatique dans la gestion du travail bancaire. 1998. Thèse (Doctorat en Ergonomie - École Pratique des hautes Études, Paris.

GOLDFINCH, S. Pessimism, computer failure, and information systems development in the public sector. Public Administration Review, v.67, n.5, p.917-929, 2007

GUÉRIN, F. et al. Compreender o trabalho para transformá-lo: a prática da ergonomia. São Paulo: Editora Edgard Blücher Ltda, 2001. 489p.

HACKETT, E. et al. The handbook of science and technology studies. Cambridge, MA: MIT Press, 2007.

HANSETH, O.; AANESTAD, M.; BERG, M. Actor-network theory and information systems. What's so special? Information Technology \& People, v.17, n.2, p.116123, 2004. [Doi: 10.1108/09593840410542466] 
HEEKS, R. Information Systems and Developing Countries: Failure, Success, and Local Improvisations. The Information Society, v. 18, n.2, p.101-1 12, 2002. [doi: 10.1080/01972240290075039]

HIGHSMITH, J. Agile software development ecosystems: problems, practices, and principles. AddisonWesley, 2002.

HIRSCHHEIM, R.; KLEIN, H.; LYYTINEN, K. Exploring the intellectual structures of information systems development: A social action theoretic analysis. Accounting, Management and Information Technologies, v.6, n.1-2, p.1-64, 1996. [doi: 10.1016/09598022(96)00004-5]

HUTCHINS, E. Cognition in the wild. Cambridge: MIT Press, 1995.

KLEIN, H.; KLEINMAN, D. The social construction of technology: structural considerations. Science, Technology \& Human Values, v.27, n.1, p.28-52, 2002.

LATOUR, B. Reassembling the social: an introduction to actor-network-theory. Oxford: Clarendon, 2005. $301 \mathrm{p}$.

LATOUR, B. Science in action: how to follow scientists and engineers through society. Cambridge, MA: Harvard University Press, 1987.

LYYTINEN, K.; ROBEY, D. Learning failure in information systems development. Information Systems Journal, v.9, n.2, p.85-101, 1999. [doi:10.1046/j.13652575.1999.0005 1.x]

ORLIKOWSKI, W.; IACONO, S., Research commentary: desperately seeking the 'IT' in IT research a call for theorizing the IT artifact. Information Systems Research, v.10, n.2, p.121-34, 2001.

PIDERIT, S. Rethinking Resistance and Recognizing Ambivalence: a multidimensional view of attitudes toward an organizational change. The Academy of Management Review, v.25, n.4, p. 783-794, 2000.

PINHO, D.; ABRAHAO, J.; FERREIRA, M. As estratégias operatórias e a gestão da informação no trabalho de enfermagem, no contexto hospitalar. Revista Latino-Americana de Enfermagem, v.1 1, n.2, p.168-176, 2003.

REYNAUD, J.D. Les règles du jeu. L'action collective et la régulation sociale. Paris: Armand Colin, 1989.

SAUER, C. Why information systems fail: a case study approach. Oxfordshire, UK: Alfred Waller Ltd., 1993. 369p.

SMITH, M.R.; MARX, L. (Eds.). Does technology drive history? the dilemma of technological determinism. Cambridge, Mass: MIT Press, 1994. 280 p.

SUCHMAN, L. Supporting articulation work. In: KLING, R. (Ed.). Computerization and controversy: value conflicts and social choices. San Diego: Academic Press, 1996. p.407-423.

TAYLOR, J. Managing information technology projects: applying project management strategies to software, hardware, and integration initiatives. AMACOM/American Management Association, 2003. 304p.

VINCK, D. (Ed.). Everyday engineering: ethnography of design and innovation. Cambridge, MA: MIT, 2003.

WAGER, K.; WICKHAM LEE, F.; GLASER, J. Managing health care information systems: a practical approach for health care executives. Jossey-Bass, 2005. 528 p.

WILSON, M.; HOWCROFT, D. Re-conceptualising failure: social shaping meets IS research. European Journal of Information Systems, v. 1 1, p.236-250, 2002.

YASNOFF, W. et al. Public Health Informatics: Improving and Transforming Public Health in the Information Age. Journal of Public Health Management Practice, v.6, n.6, p.67-75, 2000.

\section{Sobre os autores}

\section{Dominique Vinck}

Dominique Vinck é Professor em Sociologia na Universidade Pierre Mendès France, Grenoble (França). É membro do laboratório PACTE (CNRS/Universidade de Grenoble) da qual dirige o dispositivo transversal "Ciências - sociedade". Suas investigações levam sobre a Sociologia das ciências e a inovação, em especial no domínio do micro e nanotecnologias. Tem publicado recentemente: Ingénieurs au quotidien. Ethnographie de l'activité de conception et d'innovation (PUG, Grenoble, 1999) (edição americana, MIT Press, 2003), Pratiques de l'interdisciplinarité (PUG, Grenoble, 2000), Sciences et sociétés. Sociologie du travail scientifique (A.Colin, Paris, 2007) e L'équipement de I'organisation industrielle. Les ERP à I'usage (Hermès, Paris, 2008).

\section{Gloria Zarama}

Gloria Zarama é assistente de investigação em Sociologia na Universidade Pierre Mendès France, Grenoble (França). É membro do dispositivo "ciências - sociedade" do laboratório PACTO (CNRS/Universidade de Grenoble). Suas investigações levaram sobre a informatização ao hospital e sobre a etnografia das ciências. 